\title{
Waste management strategy and development in Ajman, UAE
}

\author{
Riadh Al-Dabbagh* \\ Ajman University, Ajman, UAE
}

Received: 19 February 2021 / Received in final form: 15 March 2021 / Accepted: 16 March 2021

\begin{abstract}
Population growth, social and industrial activities have increased significantly, resulting in an increase in the quantities of wastes in UAE in specific the Emirate of Ajman. Most of the waste is still not thoroughly treated and ends up in municipal landfills, where organic waste generates many gases such as methane, a potent greenhouse gas. Currently, little of the waste is burned, and the rate of municipal waste recycling has been rapidly rising. Waste management in the Ajman is coordinated through local authorities. For this purpose the UAE has set Key Performance Indicators (KPIs) to measure its performance against its targets of 2021. To support the national efforts, Ajman is continuously seeking to adopt vital initiatives and projects that are positively affecting all aspects of life. Waste issues are handled through recycling and converting waste to energy and resources, new technologies and improved waste separation and collection systems. Ajman Municipality and Planning Department has initiated plans and efforts in waste management, including converting waste to energy, treating wastewater, and controlling the movement of hazardous waste. The programs are implemented with the aim to reduce the adverse per capita environmental impact of the city, including by paying particular attention to air quality and all types of waste. The paper presents an overview of the waste situation and the management practices according to the Municipality's plans and strategies. It is concluded that Ajman still lacks an infrastructure for organic waste recycling for residents. This organic waste is a significant contributor to methane emissions from landfills. Challenges are to be solved, such as the lack of adequate waste sorting and recycling facilities in the Emirate and weak community culture to adopt waste sorting. Many practices started to be implemented by the Municipality, for instance, creating an incinerator used to treat non-chemical medical waste generated from hospitals \& clinics. As a result, Ajman has witnessed a reduction in the quantity of waste dumped in the landfill.
\end{abstract}

\section{Introduction}

To ensure sustainable development while preserving the environment, the United Arab Emirate (UAE) have set a vision for 2021 National Agenda to achieve a perfect balance between economic and social development. In this aspect, the Agenda focuses on improving air quality, increasing the contribution of clean energy, preserving water resources, and implementing green growth plans [1]. It is therefore believed that leading telecommunications infrastructure will allow the UAE to become a forerunner in the provision of Smart services. For this purpose, the UAE has set Key Performance Indicators (KPIs) to measure its performance against its targets of 2021. They are [1]:

- Decreasing the water scarcity index;

- Improving the air quality index;

- Improving the quality of air transport infrastructure;

\footnotetext{
* e-mail: riadhdabbagh46@gmail, com
}

- Improving the percentage of treated waste of total waste generated;

- Improving the share of clean energy contribution;

- Improving the Networked Readiness Index (telecommunication and IT sectors);

- Improving the quality of port infrastructure;

- Improving the logistics performance index;

- Improving the quality of overall infrastructure (such as transportation, electricity and telephone lines);

- Decreasing the time taken to obtain a loan/house from the Government for UAE;

- Citizens;

- Improving the online services index.

In Ajman, waste management projects aim to reduce the waste production rate and utilise it through recycling, processing, and reusing through developed integrated management systems and raising society's awareness of the significance of applying sustainable production and consumption mechanisms, which represents one of the 
Table 1. Ajman population census records 2005-2017 [4].

\begin{tabular}{rrrrrrrrrr}
\hline & \multicolumn{3}{c}{ Total } & & \multicolumn{3}{c}{ National } & \multicolumn{3}{c}{ Non-national } \\
\hline Year & Total & Male & Female & Total & Male & Female & Total & Male & Female \\
\hline 2005 & 206,997 & 131,684 & 75,313 & 39,231 & 20,155 & 19,076 & 167,766 & 111,529 & 56,237 \\
\hline 2017 & 504,846 & 329,631 & 175,215 & 54,326 & 27,688 & 26,638 & 450,520 & 301,943 & 148,577 \\
\hline
\end{tabular}

\section{AJMAN POPULATION 2005}

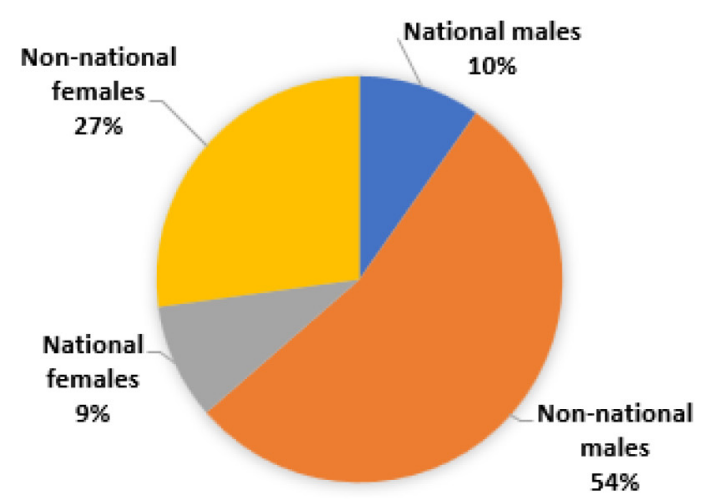

AJMAN POPULATION 2017

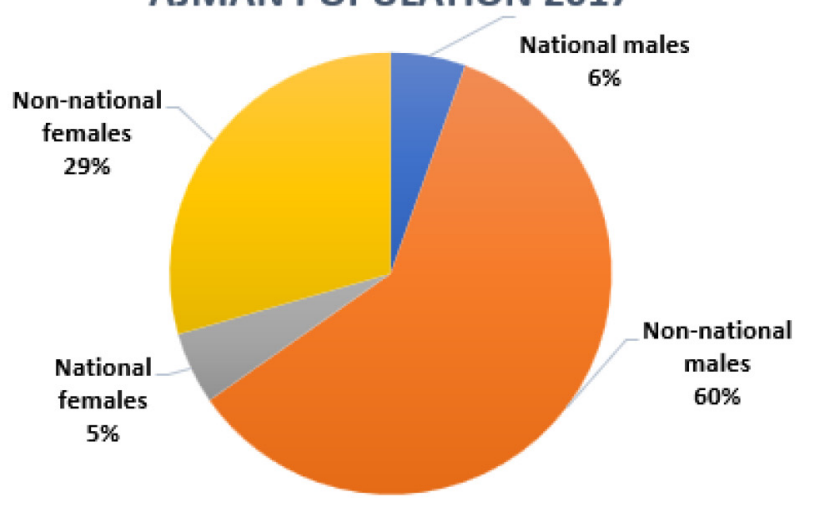

Fig. 1. Ajman population comparison 2005 and 2017 [4].

Ministry's strategic objectives [2,3]. The Ministry cooperates with the various concerned entities and institutions at the State level to realise this objective and accordingly to contribute to the realization of the UAE Vision 2021 and the UAE Centennial $2071[2,3]$.

Population and demography records in the Emirate of Ajman were collected from 2005 and 2017. According to the 2005 population census data collated by the Ajman Ministry of Economic, as shown in Table 1, most of the Emirate's population are non-nationals (81\%), with most of the population accounted for by males (63\%). Nonnational male residents comprise $66 \%$ of the total male population. Figure 1 presents the Emirate's population composition in 2005 and 2017 [4].

Chart and table of population level and growth rate for the Ajman, UAE Figure 2 metro area from 1950 to 2021. United Nations population projections are also included through the year 2035 [5].

- The current metro area population of Ajman in 2021 is

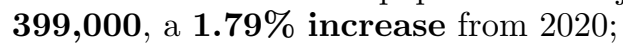

- The metro area population of Ajman in 2020 was $\mathbf{3 9 2 , 0 0 0}$, a $\mathbf{1 . 8 2 \%}$ increase from 2019 ;

- The metro area population of Ajman in 2019 was $\mathbf{3 8 5 , 0 0 0}$, a $\mathbf{1 . 8 5 \%}$ increase from 2018;

- The metro area population of Ajman in 2018 was $\mathbf{3 7 8 , 0 0 0}$, a $\mathbf{5 . 2 9 \%}$ increase from 2017.

The specific increase in population has imposed significant challenges, one of which is waste-associated management. MSW in the Emirate is collected by the Municipality or by companies contracted by the
Municipality. These waste collection companies must hold permits as only vehicles with permits can enter the landfill sites. Permits are issued for a whole year based on the estimated amount of waste generated during the period and renewed annually.

Ajman Municipality, is continuously seeking to adopt vital initiatives and projects that are positively affecting all aspects of life. The qualified and competent personnel working in the Municipality headed by his Highness Shaikh Rashid Al-Nuaimy contributed to raising awareness among all society segments, introducing them to the best practices to dispose waste and encouraging recycling to be a way of life, and according to the Federal Law No. 12 of 2018 on Integrated Waste Management, Ministerial Resolution No. 21 of 2019 on the use of recycled aggregates from construction and demolition waste for road construction and other infrastructure projects.

\section{Improvements in waste managemnt}

Ajman Municipality and Planning Department (AMPD), has initiated several practices in to continousely improve the waste correlated management strategies. Improvements to the waste management practices can be seen in Figure 3 and Table $2[6]$. This is due to the new initiatives the Ajman Municipality and Planning Department has followed to improve values from collecting, segregating and treating.

Most of the non-hazardous waste is taken to the Landfill, see Figure 4 [4]. 

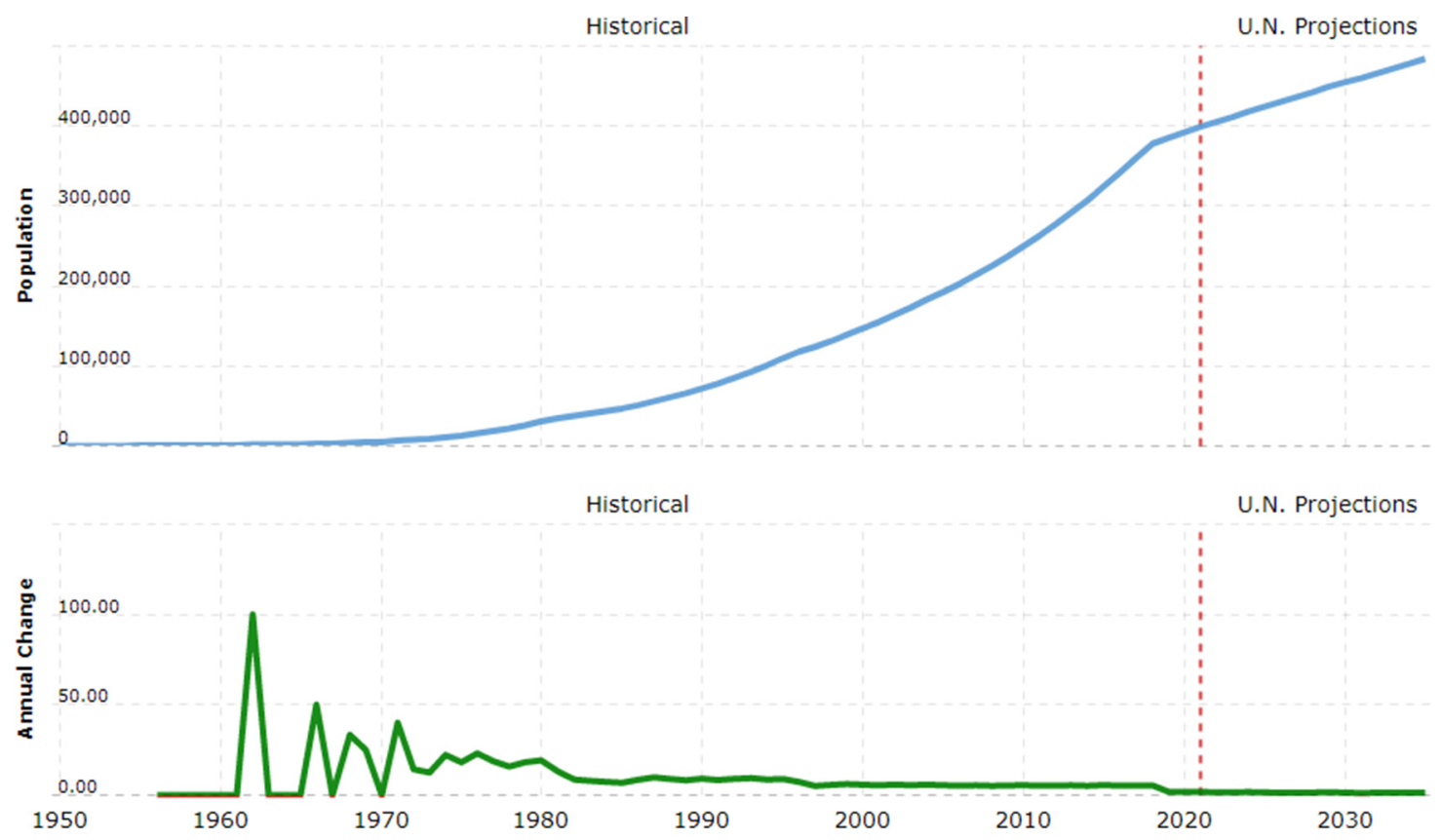

Fig. 2. Population level and growth rate for the Ajman [5].
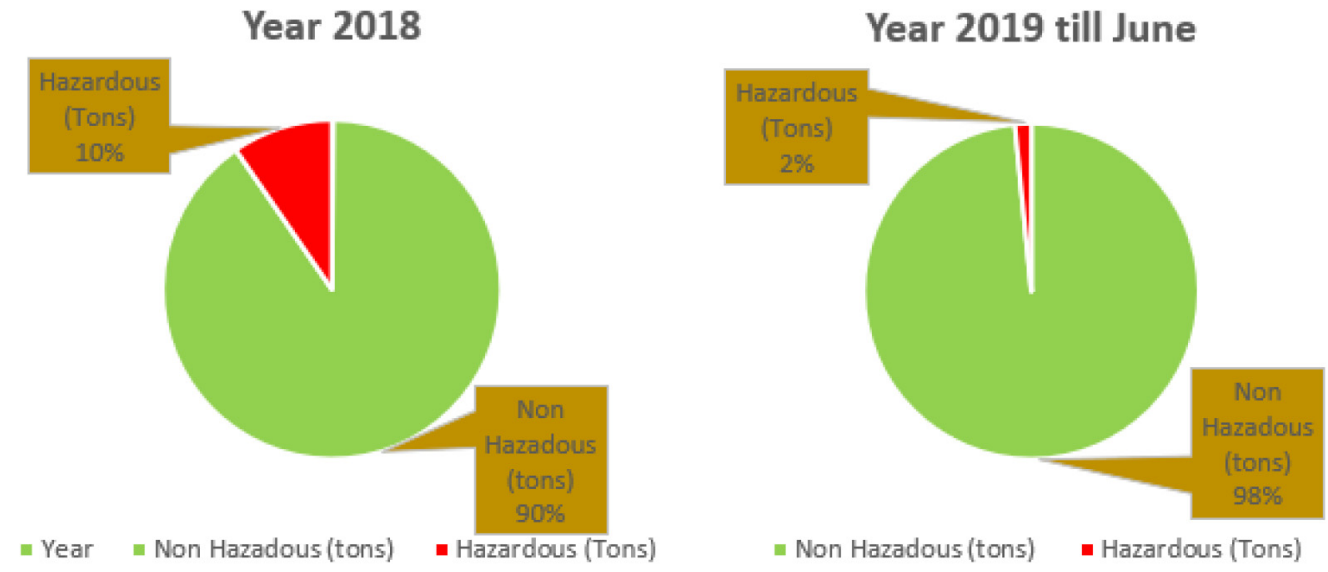

Fig. 3. Comparison of waste accumulation in Ajman (2018-2019) [6].

Table 2. Waste accumulation in Ajman in tons (2018-2019) [6].

\begin{tabular}{llc}
\hline Year & $\begin{array}{l}\text { Non-Hazardous } \\
\text { (tons) }\end{array}$ & $\begin{array}{l}\text { Hazardous } \\
\text { (Tons) }\end{array}$ \\
\hline 2018 & 1236117 & 131745 \\
2019 till June & 443307 & 7123 \\
\hline
\end{tabular}

The non-hazardous waste contains Municipal Solid Waste (MSW), Sludge, Industrial, Agriculture, Construction \& Demolisioning (C\&D) and others. Table 3 shows the percentages for each type of non-hazardous waste [6].

\section{UAE recycling guide}

UAE has always trying to introduce the latest technology and activities to control and improve the waste management [7]. Steps for Waste Disposal in UAE are taken in [8]: - Reduce Waste. Think before you use any single-use, disposable item;

- Reuse waste. Instead of throwing away your unwanted or waste item, you can repurpose, upcycle your waste;

- Donate unwanted items;

- Recycling.

Recycling activities have been well trained and practiced in all UAE. Recycling centers in the UAE, have given the opportunity for all residential, authorities and 

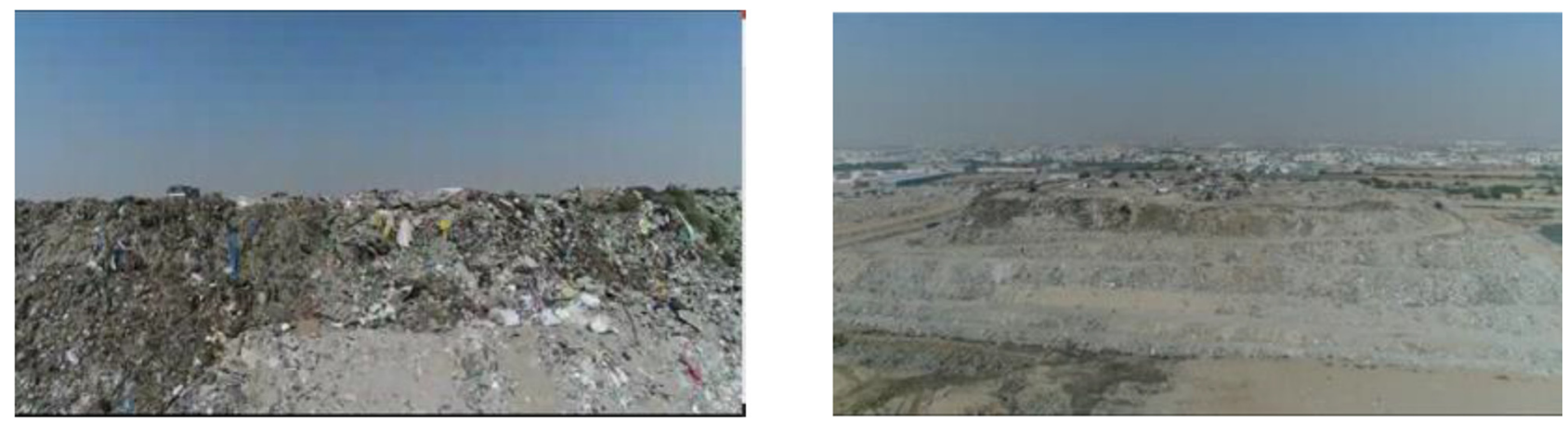

Fig. 4. Ajman Landfill [4].
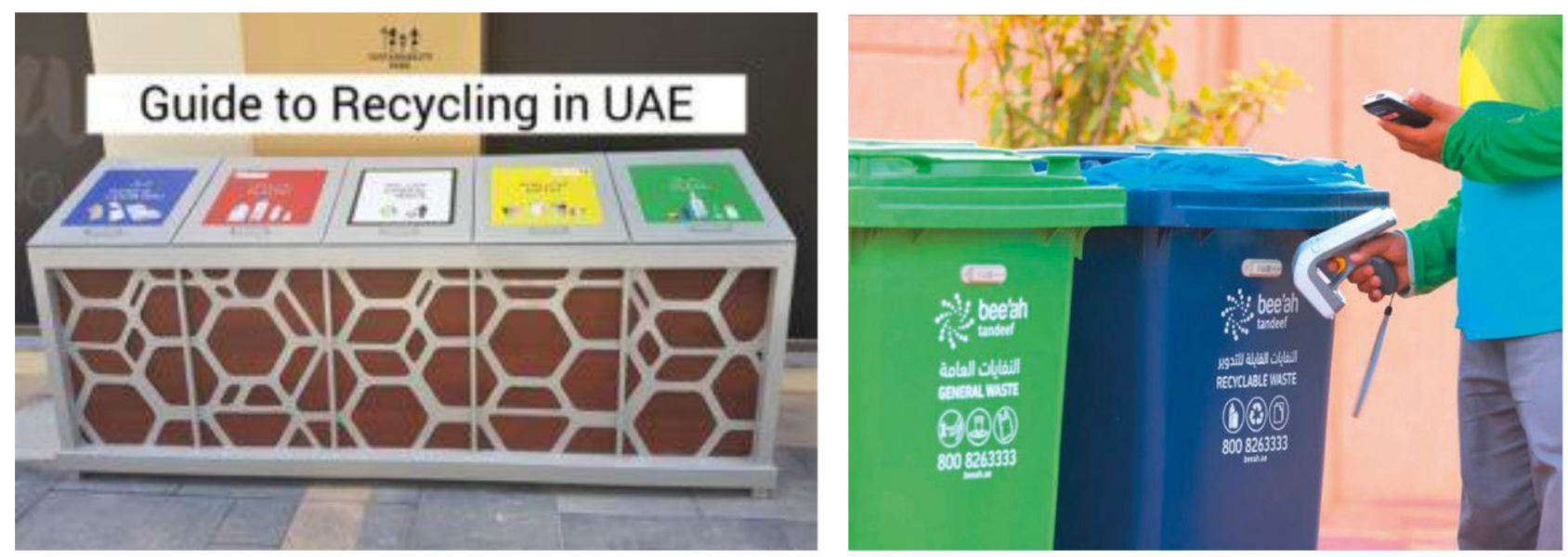

Fig. 5. Recycling guides and bins [8].

Table 3. Non-hazardous wast (2018-2019) [6].

\begin{tabular}{ll}
\hline Waste categories & Percentage \\
\hline Municpal solid waste & $28 \%$ \\
Construction \& demolisioning & $44 \%$ \\
Sludge & $3 \%$ \\
Agriculture & $3 \%$ \\
Industrial & $3 \%$ \\
Others & $19 \%$ \\
\hline
\end{tabular}

industrial sections to recycle most of their waste in in the last ten years. Residence have been enabled recycling by the segrargation bins and guidance provided by municipalities, Figure 5 [9].

Inspite of these efforts, the recyclable waste items in many cases end up in the landfill or even worst in oceans putting a heavy burden on the Natural ecosystem of which we humans are also a part of. Lack of public awareness resulted in bad behaviours which made many do not realize how many resources are wasted just by a small decision of every individual if they decide to dump the unwanted item in the waste bin instead of recycling it.

\section{Strategic steps for waste disposal}

To reduce the negative impact on ecosystem, it is very important to learn sustainable waste management practices and follow the right steps for waste disposal [10].

\subsection{Reduce waste}

Thinking before using any single-use, disposable item. Then replacing those items with reusable items so that the waste is reduced. Following guidance for how to reduce single-use plastic waste with some simple lifestyle changes.

\subsection{Reuse waste}

Instead of throwing away the unwanted or waste item, a repurpose through upcycling the general waste. This is a great resource for reusing the household items. To try zero waste lifestyle like normal family, it recommended to follow quick know-how about what is reusing, re-purposing and up-cycling.

It is also recommended to reuse the available containers, bags while shopping. This has been practiced over 1.5 years and found that it is important to educate the public 


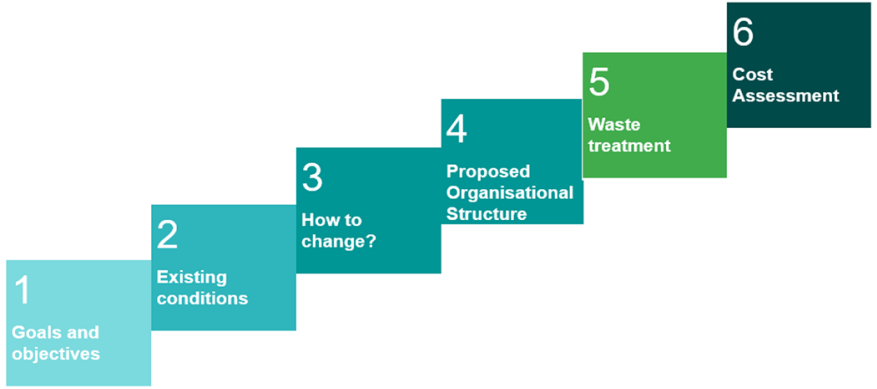

Fig. 6. The proposed Agenda for the solid waste strategy [11].

to avoid taking most of the packaging material home, which could reduce the need for frequent recycling.

\subsection{Donate unwanted items}

Now most of the times, public behaves to throw away items which are still functioning well or in good condition just because they want to buy new ones or they no longer need them. It is vital in this case to remember that one man's junk is another man's treasure and donation of those items in good condition to charities could well bring good results for the Emirate of Ajman. The government has encouraged many charities and organisations, where the public can donate your unwanted items.

\subsection{Recycling}

Segregating waste following the right procedures while recycling has been found the best for an efficient recycling process that can be introduced. Guides would contribute in a better understanding for the public when provided by the right guidance. This guide if distributed to all sectors can help people recognize which items to recycle and which of them not.

\section{Ajman solid waste strategy}

Plans were set for introducing the best solid waste strtategy looking forward for supporting the national vision. The process is summarised in Figure 6 [11].

\subsection{Goals and objectives}

The objective of the Ajman solid waste management strategy is to develop a waste management strategy for the Emirate of Ajman that [12]:

- Achieves the federal and local emirate targets;

- Avoids landfill where ever possible;

- Promotes recycling and education and awareness;

- Propose policies to enhance waste management governance, resourcing and staff capacity building;

- Provides an infrastructure plan to enable the treatment of all waste streams arising within Ajman;

- Develop a comprehensive implementation plan to guide Ajman Municipality to achieve the strategy targets;

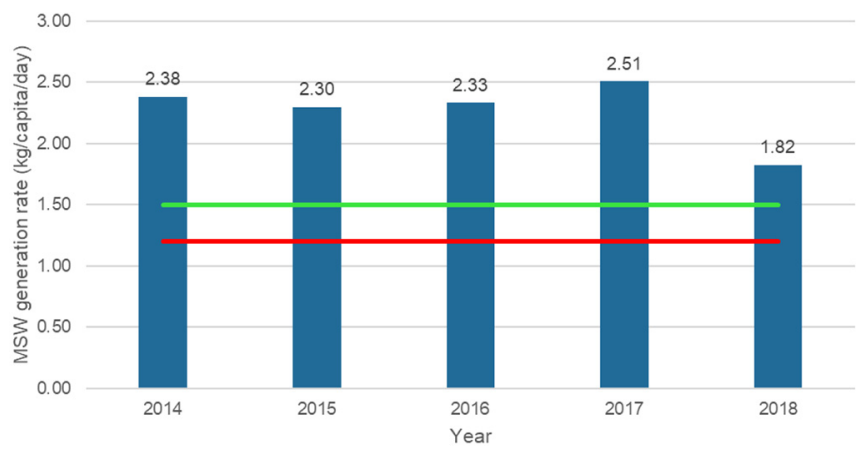

Fig. 7. recorded per capita waste generation with targets for Ajman [11,12].

- Identify future waste management costs, potential sources of funding and revenues.

\subsection{Assessment of the existing condition}

Figure 7 shows the recorded per capita waste generation rates for each year and the bars as well as the two KPI targets that should be met by implementing the waste strategy. The Federal target is to generate $1.5 \mathrm{~kg} /$ capita/day waste by 2021 and the Emirate of Ajman strategy target to generate $1.2 \mathrm{~kg} /$ capita/day waste by $2035[11,12]$.

Municipal Solid Waste (MSW), industrial (IW) and other non-hazardous waste (NHW) streams are currently disposed of in landfill with a small quantity sent to the Ajman Materials recovery facility. These waste streams are all potentially suitable for processing by the UAQ RDF facility. The figure shows that the available RDF facility annual capacity is insufficient to accept and process the quantity of waste arising from MSW, industrial and other non-hazardous waste streams projected to arise in Ajman. It should be noted that the RDF does have the capacity to treat all of the MSW however is insufficient to treat MSW, industrial and other non-hazardous waste (commercial and industrial waste streams), all of which require to be diverted away from landfill to meet Ajman Municipalities objective of minimising waste to landfill [13]. As confirmed during a meeting with the RDF facility developer, the RDF will accept commercial and industrial waste [11,12]. Figure 8 [13] shows:

- MSW, Commercial and Industrial (C\&I) waste will be sent to RDF;

- Maximum RDF capacity is reached by end of 2020 if all three wastes are sent;

- Alternative solution developed as part of the Ajman waste strategy.

\section{Possible approaches to waste management}

Efforts by the AMPD were distinctive through many activities within the planned strategy for the waste 


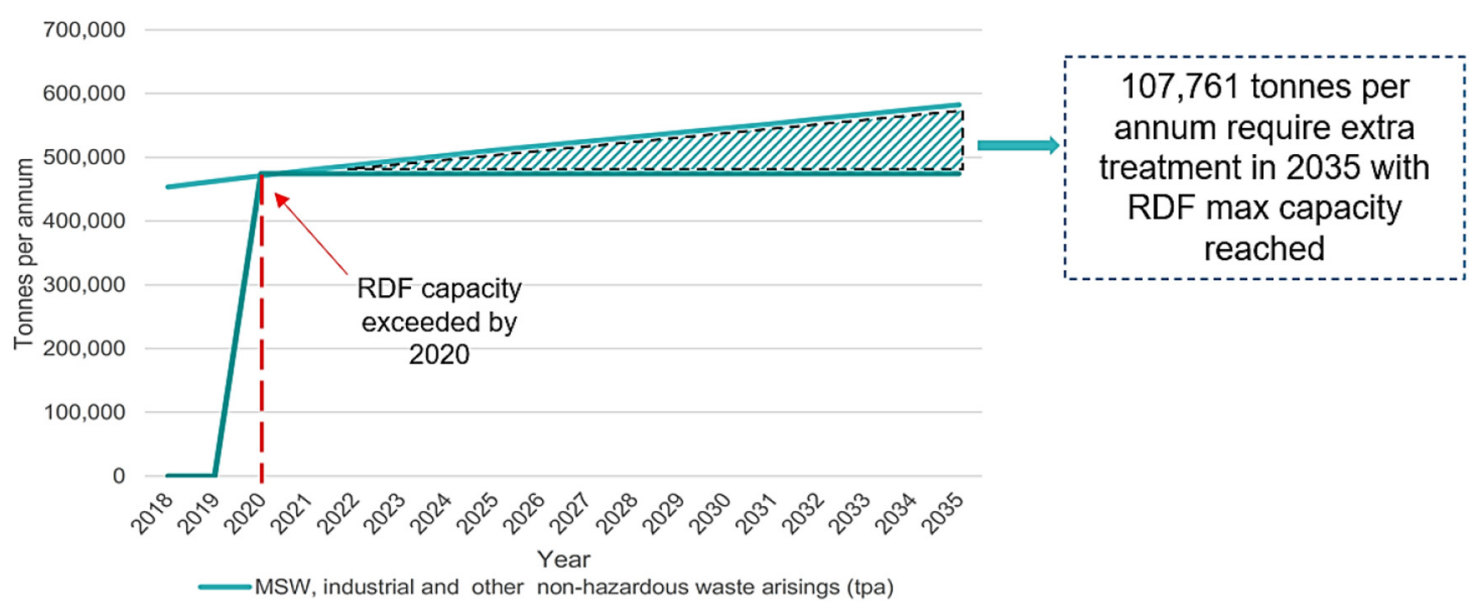

Fig. 8. Projected total waste generation vs RDF capacity [13].

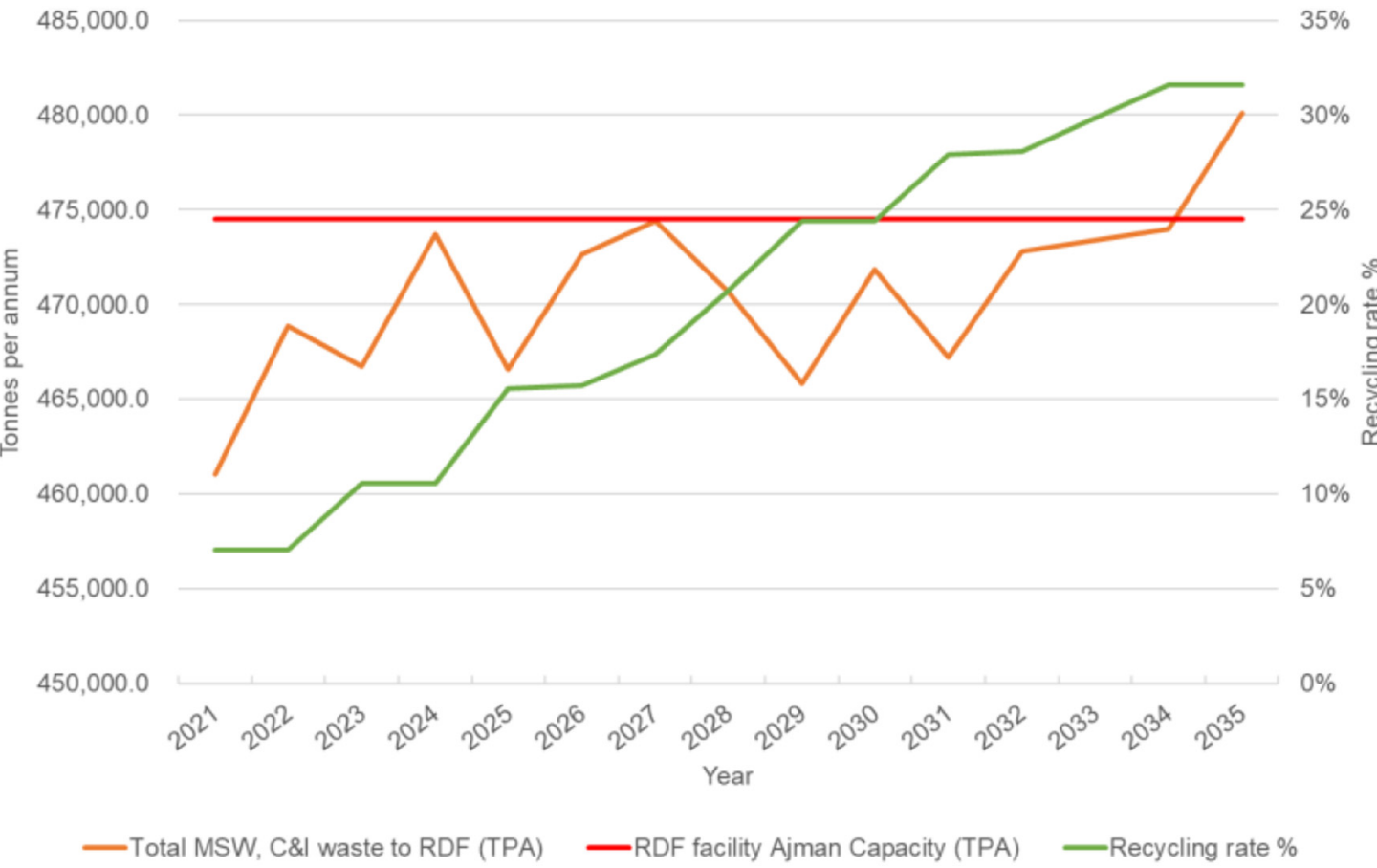

Fig. 9. The recommended approach to waste management in Ajman [12].

management introduced by the Planning Department at the Ajman Municipality aimed to enable the Emirate of Ajman to divert as much of its waste from landfill having the MSW recycling phased in. Following this stage and as mentioned earlier, the remaining MSW and CW\&IW waste is sent to the RDF facility. This has been monitored and recorded; Figure 9 presents the recommended approach to waste management with a significant increase in the recycling rates over time. The figure shows a recycling rate of $4 \%$ [12].

It is clear from Figure 7 that a significant difference in MSW, CW, and IW management in the cases of with and without recycling line would show a steady increase in waste generation in line with the population increase data shown in Figures 1 and 2. On several occasions and with the
Emirate visions, the recycling rate is realistically increasing, specifically years $2023,2025,2029,2031$, and 2034 . The increased targets enable Ajman to continue to avoid landfills by remaining below the RDF capacity line in red. The year 2035 shows an increase above the line as the strategy should be reviewed and renewed this year.

\section{Time-based KPIs and targets}

In the earlier sections, the Municipal Construction and Demolition Waste (CW \& DW) are decreasing as the recycling rate increases within time, and an important issue has arisen. This is to find a proper solution to moderate this waste-associated problem. Encouraging private companies 
Table 4. Forecast of the waste management key performance positions [12].

\begin{tabular}{|c|c|c|c|c|}
\hline KPI & 2021 Target & 2026 Target & 2031 Target & 2035 Target \\
\hline$\%$ of MSW and C\&I landfilled & $25 \%$ & $10 \%$ & $10 \%$ & $5 \%$ \\
\hline MSW recycling \% & $7 \%$ & $16 \%$ & $28 \%$ & $32 \%$ \\
\hline MSW generation rate reduction & $1.5 \mathrm{~kg} /$ capita/day & $1.4 \mathrm{~kg} /$ capita/day & $1.3 \mathrm{~kg} /$ capita $/$ day & $1.2 \mathrm{~kg} / \mathrm{cap}$ ita/day \\
\hline $\begin{array}{l}\% \text { of C\&D waste recycled of } \\
\text { beneficially used }\end{array}$ & $80 \%$ & $81 \%$ & $82 \%$ & $83 \%$ \\
\hline$\%$ of $C \& D$ waste landfilled & $20 \%$ & $15 \%$ & $14 \%$ & $13 \%$ \\
\hline$\%$ of Horticultural waste composted & N/A & $50 \%$ & $70 \%$ & $100 \%$ \\
\hline Material capture at MRF & $10 \%$ (Dirty MRF) & $80 \%$ (Clean MRF) & $90 \%$ (Clean MRF) & $90 \%$ (Clean MRF) \\
\hline
\end{tabular}

was the solution to increasing recycling capacity and the sale of products. Therefore, Ajman's waste strategy KPIs and targets were developed to meet Federal waste targets to minimize the waste sent to the landfill. This is clear in Table 4 [12]. AMPD has consequently Suggested operational KPI: Waste segregation from MRF to improve material recovery at the MRF to $90 \%$ (Clean MRF).

To achieve the above-mentioned targets, it is recommended that a specific infrastructure strategy and framework be followed as suggested by [12] Figure 10.

Moreover, the institution and Governance strategy was prepared with an Institutional framework following the progress of waste associated rate and the ongoing developments to achieve the Federal targets. Figure 11 is a suggested framework by [12].

The AMPD [12] has done cost strategical analysis, and a financial framework was initiated, as shown in Figure 12.

\section{UAE federal law aims at $75 \%$ of waste recycling}

As per the national aim to regulate managing waste, disposal methods to reduce harm to the environment, cutting the total amount of waste produced and using waste for alternative purposes a Federal law, the first in the region, given the fact that the UAE generates more than 6.5 million tonnes of waste per annum. UAE's integrated waste management, which combines a variety of strategies for both waste management and waste reduction aims at recycling $75 \%$ of municipal solid waste generated rather than dumping it in landfills [14]. The UAE's per capita waste generation is around 1.2 to 1.3 kilogram per day which is among the world's highest, the majority of which or $77 \%$ ends up in landfills, the UAE's integrated waste management, which combines a variety of strategies for both waste management and waste reduction aims at recycling 75 per cent of municipal solid waste generated rather than dumping it in landfills.

\section{United arab emirates approaching zero waste}

Following the UAE goal is to divert 75 percent of waste from landfills by 2021, the UAE started to intensify its recycling efforts. In this aspect the UAE aiming to be one of the best countries in the world by the year 2021 .

In UAE, federal government authorities handle core policy and service delivery portfolios including foreign relations, interior policies and services as well as environmental policy, education and health, to name but a few. Local governments are responsible for the delivery of municipal services such as waste management, local urban planning, land usage, sewerage, sanitation, economic licensing, local roads, public transportation and so forth in accordance with federal policies, strategies and standards. However, each emirate has considerable autonomy to shape their development trajectories using UAE's national vision - Vision 2021-as a template for forward planning. In response the Emirate of Dubai, a recycling hub was set for early 2019. The electronics recycling facility features zeroto-landfill and zero-to-air process. The Emirate of Sharjah, which is heading for zero waste to landfill, had set up a municipal waste management company Bee'ah in 2007 in the form of a public-private partnership [15]. Bee'ah's has made a partnership with Masdar (the Abu Dhabi future energy company) to explore alternative energy sources, to develop a new waste-to-energy facility, which will incinerate up to 35 tons of solid waste per hour. "The power produced by this facility will be added to that produced by 
Waste transfer station

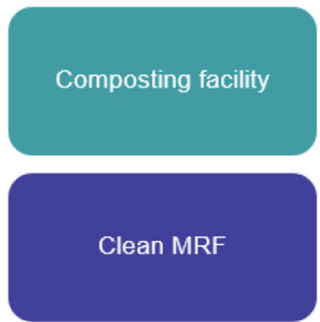

Waste collection contracts
- Transfer station required to reduce cost of waste transfer to RDF.

- To divert green waste away from landfill.

- Conversion of MRF to clean MRF through source segregation of dry recyclables. No capital investment required

\section{- Existing collection contracts have the following shortfalls:}

- Insufficient service definition (task buffer zones, frequencies, specifications)

- Does not allow for source segregation and recycling

- Does not allow for accurate classification recording of separate waste streams

Fig. 10. Recommended that a specific infrastructure strategy and framework.

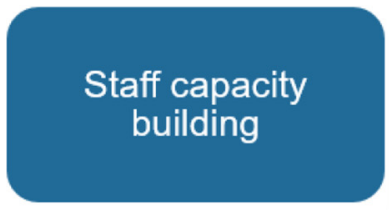

- Ajman strategy builds an efficient waste department within Municipality to achieve strategy objectives such as recycling, landfill diversion, procurement of infrastructure, education and awareness, classification system and monitoring and enforcement

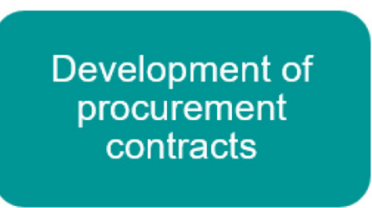

- Procurement contracts required for new infrastructure including transfer station and compost facility. Updated contracts required for waste collection contracts as a result of the shortfalls identified previously

\section{Promote waste minimisation}

- Waste minimisation helps Ajman to send its MSW and C\&I waste to the RDF facility and avoid landfill

Fig. 11. institution and Governance strategy and framework.

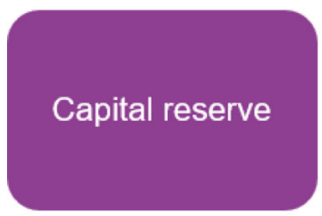

The current waste management infrastructure in Ajman is deemed insufficient to achieve the Federal and emirate level waste targets. Capital reserve of 133 million AED is required for investment in future waste management infrastructure (transfer station, compost facility waste collection contracts CAPEX and first year OPEX).

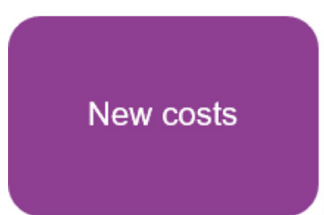

The strategy includes new CAPEX (13 Million AED) and OPEX (120 million AED

$2021)$ costs. The OPEX cost is annual and will increase with inflation.

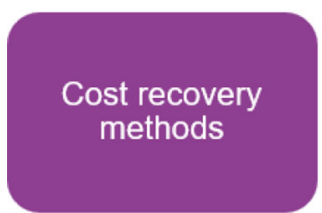

The cost of new infrastructure must be recovered through increased charges or covered by Ajman government

Fig. 12. Cost strategy and financial framework. 

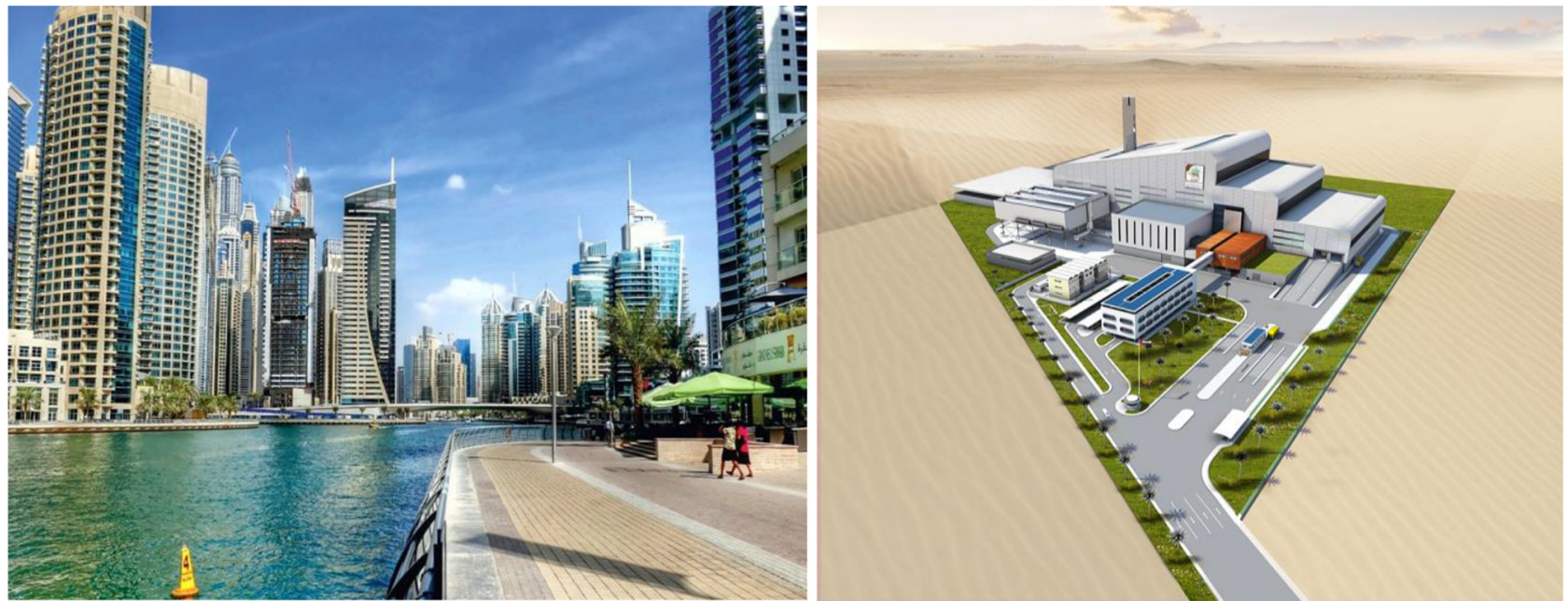

Fig. 13. UAE typical buildings and the world's largest energy from waste plant built in the Emirate of Dubai [15].

Bee'ah's gasification plant, to supply a total of $90 \mathrm{MW}$ of green energy, to the Sharjah electricity grid" [15]. It was announced that, the facility is due for completion by early 2021 ; it aims to achieve the emirate's zero-waste-to-landfill target and the UAE's goal of diverting 75 percent of its municipal solid waste from landfill by 2021. Figure 13 shows the type of buildings and the world's largest energy from waste plant built in the Emirate of Dubai which explains the amount of efforts and why they are heading for zero waste is possible.

\section{Conclusions}

All types of waste products produced in the Emirate of Ajman will be controlled and managed more efficiently in the near future. The local authorities are already going through extreme measures to keep everything a safe and controlled place and environment. The health and safety of the citizens come first which is why they are already creating new innovations and systems for controlling how to get rid of the waste without it affecting the environment and there for prevent pollution. New innovations and creations are being made for this type of issue all throughout the world and scientists are still learning new ways on how to be even more safe when dealing with the environment or when dealing with pollution. This article explores the amount of efforts that the UAE is putting and specifically the Emirate of Ajman in order to meet their targets for $75 \%$ recycling and no landfill. Many associated KPIs were discussed that the Government is using to construct their strategies for an improved waste management. Achievements were clear from the presented data. Modern practices and facilities were shown that have been introduced by Ajman Municipality and Planning Department which contributed in that achievement and made the vision setup for 2021 real. Guides and recommendations with proposed Agenda were introduced to support the Gvernment overall intensive efforts to waste.

\section{References}

1. UAE, 2020. Environment and government agenda. [Online] Available at: https://u.ae/en/information-and-services/en vironment-and-energy/environment-and-government-agenda [accessed 22 January 2021]

2. AMPD, 2019. Municipality and Planning Department discusses the integrated waste management projects and Ajman landfill with the Ministry of Climate Change and Environment. Department, Ajman Municipality and Planning. [Online] Available at: https://www.am.gov.ae/mediacenter/press-news/municipality-and-planning-departmentdiscusses-the-integrated-waste-management-projects-andajman-landfill-with-the-ministry-of-climate-change-and-en vironment [accessed 15 February 2021]

3. UAE, 2020. Waste management. [Online] Available at: https://u.ae/en/information-and-services/environment-andenergy/waste-management [accessed 15 February 2021]

4. AMPDR (2019). Ajman Waste Management Strategy: Gap Analysis Report. Ajman Municipality and Planning Department, Mott MacDonald. Requested through official communications

5. GulfNews, 2018. New UAE federal law aims at $75 \%$ of waste recycling. [Online] Available at: https://gulfnews.com/uae/ environment/new-uae-federal-law-aims-at-75-of-waste-recy cling1.2218395\#: : text=The\%20new\%20legislation\%20reg ulates \% 20managing, using \% 20waste\% 20 for \% 20alternative \%20purposes. [accessed 18 February 2021]

6. Municipality \& Planning Department, 2019. City of Ajman Population and Waste management. Data requested by official communications

7. AMPD19-20, (2021). Waste Management Database (2019 2020). Requested through official communications. Ajman

8. LakshmiBaalaHospital, 2019. Recycling Companies in Sharjah. [Online] Available at: https://lakshmibaalahospi tal.blogspot.com/ [accessed 15 February 2021]

9. GulfNews, 2019. Sharjah residents get blue, green bins to segregate waste. [Online] Available at: https://gulfnews. $\mathrm{com} /$ uae/sharjah-residents-get-blue-green-bins-to-segregatewaste-1.65526712 [accessed 12 February 2021]

10. S. Rajagopal, I. Bansal, Waste disposal of fresh fruits and vegetables: a study of consumers' awareness levels in the 
United Arab Emirates (The UAE), Manag. Environ. Qual. 26, 721-738 (2015)

11. AMPD20 (2020). Ajman Municipality and Planning Department, Contingency Plans For Hazardous Waste Management (Crises and Disasters), Planning Department. Private communications

12. AMPD20-21 (2021). Ajman Solid Waste Strategy. Waste management strategy presentation by M. Macdonald. Report by the Ajman Municipality and Planning Department Ajman - UAE. Official communication
13. S. Bose, S. Chakrabarty, D. Ghosh, Support vector regression-based Monte Carlo simulation of flexible water clusters, ACS Omega 5, 7065-7073 (2020)

14. S. Salama, (2018, May 8). New UAE federal law aims at $75 \%$ of waste recycling. Gulf News. Retrieved from https:// gulfnews.com/uae/environment/new-uae-federal-law-aimsat-75-of-waste-recycling-1.2218395

15. Global Recycling, 2021. United Arab Emirates: On the Road to Zero Waste. [Online] Available at: https://global-recycling. info/archives/2623 [accessed 18 February 2021]

Cite this article as: Riadh Al-Dabbagh, Waste management strategy and development in Ajman, UAE, Renew. Energy Environ. Sustain. 6, 14 (2021) 